\title{
Analysts' forecasts and uncertainty about firm value
}

Angela Andrews, Pradyot Sen, Jens Stephan

\section{Introduction}

Financial analysts' forecasting process is sometimes described as a "black box" in the literature and other than a survey (Brown et. al., 2015) very few insights can be gained about the forecasting process. Therefore, it is even more important to investigate the properties of the analysts' forecasts to calibrate how they capture market information and how the market captures their information. It is generally accepted that a rich information environment and low information asymmetry between management, financial intermediaries, and investors have beneficial effects on the efficient functioning of capital markets. The benefits typically include efficient pricing, better earnings forecasts, increased liquidity and beneficial effects on risk factors such as uncertainty about firm value, cost of capital and the volatility of future stock returns (see Diamond and Verrecchia (1991), Healy and Palepu (2001), Easley and O'Hara (2004), Liu and Wysocki (2008), Kothari et al. (2009), Rogers et al. (2009), Billings et. al. (2015) among others). Increasingly, analysts' earnings forecasts are becoming a major source of new information for market participants (Brown and Caylor (2006)). In particular, an analyst forecast revision introduces two salient pieces of information, the news content (good vs. bad) which changes expectations of future cash flows and the change in dispersion of analysts' forecasts (Barron et al. 1998, Kothari et al. (2001) which has been linked to uncertainty about future earnings and stock returns (e.g., Avramov et al. (2009), Barron and Stuerke (1998), Imhoff and Lobo (1992)).

In this paper, we use implied volatilities from exchange traded options to examine the interaction between analysts' forecast revisions and the market's perception of uncertainty about firm value. We ask three questions of interest to accounting researchers. First, how does the

This is the author's manuscript of the article published in final edited form as: Andrews, A., Sen, P., \& Stephan, J. (2018). Analysts' forecasts and uncertainty about firm value. Review of Accounting and Finance, 17(3), 298-315. https://doi.org/10.1108/RAF-09-2016-0146 
market react to information conveyed by forecast revisions, i.e., how do implied volatilities change in the days surrounding a forecast revision? We examine this question in the context of two characteristics of the forecast revision; whether it conveys good or bad news and whether the dispersion of forecasts increases or decreases.

Second, do analysts incorporate the information about implied volatilities into their forecast revisions? Analysts gather and process information and then decide when to issue a revised forecast. At the time of his/her forecast revision, the analyst can observe the change in implied volatility for the stock since the prior forecast revision (most likely by a different analyst). We reverse the first question by asking whether increases/decreases in the market's perception of uncertainty about firm value affect the news conveyed by the analyst's forecast revision.

Third, a significant body of research has used the dispersion of analysts' forecasts as a proxy for uncertainty about the value of the firm, future earnings, and future stock returns (e.g., Avramov et al. (2009), Barron and Stuerke (1998), Imhoff and Lobo (1992)). With implied volatilities from exchange traded options reflecting a market transaction based metric for uncertainty, it is possible to test the extent to which dispersion of analysts' forecasts reflects the market's perception of uncertainty.

Our work builds on prior accounting research that has examined how information provided by management and by analysts is used by market participants, particularly in setting prices. ${ }^{1}$ They also conclude that the higher credibility and timeliness of articles in the business press result

\footnotetext{
${ }^{1}$ More recent research has shifted the focus to risk effects. Kothari et al. (2009), for example, investigated how Management Discussion \&Analysis (MD\&A) in the 10K report, analyst valuation reports, and articles in the business press affect firm risk as measured by future cost of capital, dispersion of analyst forecasts, and stock return volatility. Good (bad) news was hypothesized to reduce (increase) the risk metrics. The credibility and timeliness of the three sources of information were also key parameters expected to impact the three firm risk factors. Kothari et al. (2009) find that good (bad) news disclosures decrease (increase) the risk metrics.
} 
in consistent and predictable reactions across the three risk metrics while the MD\&A and analyst valuation reports affected only a subset of the risk metrics.

Another recent study, Rogers et al. (2009), examined how management forecasts affected investor's perceptions of firm risk. Their study, like ours, used implied volatilities from exchange traded options $^{2}$ as the risk metric. Our paper is different from Rogers et. al. (2009) in that we examine analyst forecast revisions, which are much more frequent and, therefore, timely sources of information to the market. The same underlying information and uncertainty that influences implied volatility is also likely to cause analysts to revise their forecasts. Market participants may, therefore, learn about the information environment from a forecast revision and trade in different markets which may, in turn, affect implied volatility. Also, Rogers et al (2009) use one management forecast and therefore, the issues related to forecast dispersions cannot be addressed in their design. As a result their design cannot address how the inherent uncertainty of the forecasts affect the market perception of risk.

Implied volatilities are an improved proxy for risk (compared to future cost of capital, dispersion of analyst forecasts, and stock return volatility) for three reasons. First, finance theory suggests that implied volatilities are the market's expectation of stock return volatility over the time to expiration of the option. Second, implied volatilities are based on realized market transactions (as opposed to analysts' perceptions) and third, changes are observable immediately following an event, such as the release of a forecast revision. This permits a "short-window" analysis uncontaminated by past or future economic events that might influence the measurement of other risk metrics such as the cost of capital, the dispersion of analysts' forecasts, and stock return volatility.

\footnotetext{
${ }^{2}$ Available in the Option Metrics data base.
} 
The Kothari et al. (2009) qualitative results that the content of the news affects risk attributes such as cost of capital are confirmed in Rogers et al. (2009) who find that the good (bad) news content of management forecasts results in decreases (increases) in implied volatility. ${ }^{3}$ Jones et.al. (2014) observe that implied volatility eventually reduces after the dividend announcement and declines after dividend initiation. These observations are consistent with the understanding that good news leads to a reduction of risk.

Our results are consistent with all of these studies insofar as the changes in implied volatility on the days surrounding forecast revisions are negatively correlated with the nature of the news, i.e., good (bad) news forecasts result in decreases (increases) in implied volatility. Furthermore, we do not find evidence that analysts incorporate the information in implied volatility into their forecast revisions. Specifically, we do not find that forecast revisions are more likely to be good (bad) news when implied volatility has decreased (increased) since the prior forecast revision for the firm. Lastly, we also find evidence that changes in the dispersion of analysts' forecasts are correlated with changes in implied volatility.

We are also able to compare and contrast the results in our paper with those found in the Kothari et al. (2009) and Rogers et al. (2009) papers. Kothari et al. (2009) posit that management, analysts and the business press have decreasing incentives to optimistically bias their disclosures and, therefore, have increasing credibility in the market. They suggest that the market will discount the effect of disclosures based on the credibility of the source, i.e., news from a management disclosure will have a smaller effect on price than an equivalent disclosure by analysts. We find a substantially different effect on uncertainty when comparing management and analyst earnings

\footnotetext{
${ }^{3}$ Another example of information that may affect the uncertainty is a dividend announcement or initiation. Acker (1999) shows that a dividend announcement is associated with increases in risk and leads to an increase in implied volatility.
} 
forecasts (recall that Kothari et al. (2009) investigate the MD\&A in the 10K (not forecasts) and analyst valuation reports (not forecasts). The magnitude of the change in implied volatilities during the days surrounding a management earnings forecast (Rogers et al. (2009)) is much larger than the change in implied volatilities surrounding analyst forecast revisions (our paper). Our results indicate that the inferences about credibility and timeliness for the MD\&A vs. the analyst valuation reports may not extend to earnings forecasts made by the two groups. Finally, our multivariate examination of the correlation between dispersion of forecasts and implied volatility yields statistically significant results, although the $\mathrm{R}^{2}$ s are low. ${ }^{4}$

The remainder of this paper is organized as follows. Section 2 provides the background and hypotheses development. Section 3 describes the sample selection procedures, defines the research methodology, and provides descriptive statistics. Section 4 provides the discussion of results and Section 5 summarizes conclusions.

\section{Background and Hypothesis Development}

In this section we provide the background for our empirical predictions on the main research questions: (1) whether analysts' forecast revisions impact the market's perception of uncertainty about firm value, (2) whether analysts incorporate the observable information about implied volatilities into their forecast revisions, and (3) the degree to which analyst forecast dispersion, often used as a proxy for future stock return volatility, is correlated with implied volatilities from exchange traded options.

\subsection{Do Forecast Revisions Affect Implied Volatility?}

\footnotetext{
${ }^{4}$ Although a positive earnings surprise is the dominant factor in the market's perception of firm performance, recent work by Rees and Twedt (2011) indicates that prior downward earnings guidance mitigates the favorable market response. Relatedly, Yoo and Pae (2017) indicate that analysts attenuate the impact of negative earnings surprises by issuing more positive concurrent cash flow forecasts in order to maintain better relations with the firm's management.
} 
The first question is addressed using a short window, information content design, both in univariate format and multivariate regression. Rogers et al. (2009) find that management forecasts, on average, increase uncertainty as measured by implied volatilities on the days surrounding the forecast. We expect analyst forecast revisions to have the same effect. Relatedly, we examine whether the magnitude (absolute value) of forecast revisions is correlated with the magnitude of changes in implied volatility. Thus our first hypothesis in alternative form becomes:

Hypothesis 1A: Analyst forecast revisions increase the implied volatility of exchange-traded options around the date of the forecast.

Hypothesis 1B: The absolute magnitude of forecast revisions is positively correlated with the absolute change in implied volatility of exchange-traded options around the date of the forecast.

Kothari et al. (2009) posit a directional link between the nature of news and risk measures such as cost of capital. In an efficient market price changes are a result of new information about the magnitude and direction of cash flows and/or about the risk of the cash flows. Even if information about the magnitude and risk are independent, smaller cash flows must be inherently more risky than larger cash flows (at minimum because bankruptcy risks are higher). This hypothesis is tested in a CAPM framework by and Ball and Kothari (1989) who find that the cost of capital and return volatility are negatively associated with price changes and news.

Both Kothari et al. (2009) and Rogers et al. (2009) posit the leverage effect as a reason why good vs. bad news affects risk metrics. Price increases (decreases) associated with good (bad) news decrease (increase) the firm's financial leverage, at least in market terms. ${ }^{5}$ Increases (decreases) in leverage make equity more (less) volatile and, therefore, to the extent "good news" leads to an increase in cash flow and consequently, to a lower leverage, it should be negatively

\footnotetext{
${ }^{5}$ See Black (1976), Christie (1982), French et al. (1987), Campbell and Hentschel (1992)
} 
correlated with uncertainty about firm value. We, therefore, examine whether good (bad) news forecast revisions induce decreases (increases) in implied volatility during the seven-day period centered on the forecast revision. This leads to our second hypothesis as follows:

Hypothesis 2: On average, good (bad) news forecast revisions result in decreases (increases) in implied volatility around the date of the forecast revision.

A forecast revision, just as any disclosure, besides conveying good or a bad news, ought to increase the precision of investors' beliefs about the parameters of the distribution of future payoffs, that may affect the forward-looking volatility of stock returns (Billings et. al, (2015) among others). However, analysts' forecasts embed within themselves another measure of uncertainty, their dispersion, that is absent in other disclosures. Prior research has used the dispersion of forecasts as a proxy for uncertainty (Kothari et al., 2009, Adut, Sen and Sinha 2014). Therefore, while the prior literature (Roger at. A. (2009), Billings et.al. (2015)) relates disclosure such as management forecast to implied volatility, their data and design cannot be used to directly correlate the dispersion of the disclosure (forecast) with the resultant uncertainty captured by the market ${ }^{6}$. Since the dispersions of the source news ought to be correlated with the end result, we test whether dispersion increasing (decreasing) forecast revisions lead to increases (decreases) in implied volatility during the days surrounding the forecast.

The combination of the news and dispersion effects of a forecast revision suggests a $2 \times 2$ matrix with four cells [(1) good news dispersion increasing, (2) good news dispersion decreasing, (3) bad news dispersion increasing, and (4) bad news dispersion decreasing]. Each cell has the potential to convey a different risk scenario affecting changes in implied volatility. We select the

\footnotetext{
${ }^{6}$ Tang et. al. (2014) relates the range of management earnings forecast with the Analysts Forecasts dispersion, and in spite of being a step in the right direction, a range by itself does not capture the variation that is done by the dispersion, which attempts to capture the second moment of the underlying distribution.
} 
good news, dispersion decreasing and the bad news, dispersion increasing subset for potentially extreme increases and decreases in implied volatility. This discussion leads to our third hypothesis in alternative form about the combination of information content and forecast dispersion.

Hypothesis3A: Dispersion reducing (increasing) forecast revisions result in decreases (increases) in implied volatilities around the date of the forecast.

Hypothesis 3B: The combination good (bad) news, dispersion decreasing (increasing) forecast revisions result in greater decreases (increases) in implied volatility than all good (bad) news forecast revisions.

\subsection{Are Changes in Dispersion of Forecasts Correlated with Changes in Implied Volatility?}

Accounting researchers have used the dispersion of analysts' forecasts as a proxy for uncertainty about the current value of the firm, the future performance of the firm (e.g., future earnings), and the future value of the firm (e.g., the volatility of future stock returns). Therefore,

if dispersion of forecasts is indeed a proxy for uncertainty, we would expect the change in dispersion from one forecast revision to the next one to be correlated with the change in implied volatility over the same period of time. Thus, we get Hypothesis 4, stated in the alternate form. Hypothesis 4: Changes in dispersion of forecasts are positively correlated with changes in implied volatilities during the period between forecast revisions.

\subsection{Do Changes in Implied Volatility Affect Subsequent Forecast Revisions?}

Analysts seek out and create value relevant information and then choose the time to release it through their forecast revisions. A long-standing question of interest to accounting researchers is whether analysts use all of the information at their disposal, e.g., price changes since the last forecast revision. In our context, the question is whether analysts use the observable changes in implied volatilities during the time period between forecast revisions, and whether they interpret 
a reduction (increase) in implied volatility as a signal of good (bad) news. If analysts process the information in this manner, we would expect good (bad) news forecast revisions to be associated with a prior (between forecast) period decreases (increases) in implied volatilities. If they do not use the information, we would not expect to see such an association. ${ }^{7}$ Hence Hypothesis 5 follows. Hypothesis 5: A decreases (increases) in implied volatilities during a time between forecast revision, leads to a good (bad) news forecast revision for the subsequent forecast.

\section{Experimental Design}

In this section we detail the definitions of the variables used in the analysis. First, all tests rely on the characteristics of the forecast revision. These can best be described using Figure 1 for a hypothetical current forecast revision on April 22. The prior forecast revision (usually but not necessarily by a different analyst) occurred on March 14 . Note that the characteristics of analysts' forecasts for the firm (e.g., mean and dispersion) do not change in the intervening days. We calculate the mean (AF) and standard deviation $(\sigma)$ of analysts' forecasts on each revision date. An increase (decrease) in the mean forecast is defined as good (bad) news. The mean forecast on the current (prior) revision dates is labeled $\mathrm{AF}_{\text {revdate }}\left(\mathrm{AF}_{\text {priordate }}\right)$ in the tables, respectively. The change in the mean forecast is defined as the difference in the mean forecasts divided by the stock price at the prior revision date.

Implied volatilities are defined as the implied standard deviation of stock returns (ISD) from the Black-Scholes option pricing formula. The OptionMetrics database adjusts the ISD to

\footnotetext{
${ }^{7}$ Our timeline is carefully constructed to avoid endogeneity issues between forecast revisions and implied volatility, i.e., forecast revisions may affect implied volatility and implied volatility may affect forecast revisions. This point is illustrated in Figure 2 which shows that the implied volatility (possibly) used by the analyst does not overlap with the date of the forecast revision, indeed, the forecast revision happens three days later. A forecast revision may affect implied volatility because both incorporate the same underlying uncertainties and information. This does not preclude the analyst from using all observable information, including implied volatilities.
} 
reflect a standard time to expiration $(30,60,91 \ldots$ days $)$. We use $\%$ changes in ISD's in our analysis.

The first research question asks how the market reacts to characteristics of the forecast revision - the change in ISD is, therefore, measured from day -3 to day +3 relative to the current forecast revision. ${ }^{8}{ }^{9}$ The second research question asks whether analysts incorporate the information about changes in implied volatilities into their forecasts. This case is shown in Figure 2. An analyst can observe the change in implied volatility for the firm from the date of the prior forecast to the date just prior to his current forecast revision. We chose day -3 as the last date the analyst looks at implied volatility because of concern that volatilities might change through leakage of the forecast revision. The third research question asks whether forecast dispersion is correlated with changes in implied volatility. This situation is also shown in Figure 2. In this case the change in implied volatility is measured on the days of the current and prior forecast revisions to coincide with the days on which forecast dispersion is measured.

\section{Data}

Our sample consists of the intersection of (1) firms with implied volatilities of various durations in the OptionMetrics Standardized Options dataset for the time period from 1996 to $2006,{ }^{10}$ (2) firms with analyst forecasts in the detail IBES dataset, and (3) firms with stock prices and returns in the CRSP files.

\footnotetext{
${ }^{8}$ Our experimental design is intended to capture the causality between forecast revisions and changes in implied volatility. Specifically, the event window is narrow enough to preclude the occurrence of too many extraneous events of importance and the sample size is sufficiently large to average away the effects of such events, should they occur. ${ }^{9}$ We have replicated tables 6 through 8 using 11 day (days -5 to +5 ) and three day (days -1 to +1 ) event windows. Results are qualitatively similar to those reported in the paper for the seven day (days -3 to +3 ) event window. Results are available upon request.

${ }^{10} \mathrm{We}$ recognize that time span covered by OptionMetrics is dated, but versions with more recent data are not available to the authors.
} 
Table 1 provides the basic data availability and screening procedures for options with 30 days to maturity. It shows that data availability on COMPUSTAT and CRSP reduce sample size by very little $(\sim 3.2 \%)$. This is consistent with common knowledge that larger firms tend to have exchange traded options and COMPUSTAT and CRSP have more complete data on larger firms. Table 2 illustrates that there are more exchange traded options with short durations than long durations. Table 3 provides descriptive statistics on the distribution of changes in implied volatility around forecast dates for options with durations ranging from 30 days to 730 days. The distributions appear to be symmetrically distributed around the median. The analyst following for sample firms ranges from a minimum of three (required to compute a dispersion of forecasts) to a maximum of 54 (with $25^{\text {th }}$ percentile $=8$ analysts and $75^{\text {th }}$ percentile $=20$ analysts). Similarly, the $25^{\text {th }}$ percentile for the market value of equity is $\$ 1.1$ billion and the $75^{\text {th }}$ percentile is $\$ 10.9$ billion.

\section{Discussion of Results}

This section provides the results of the empirical analysis of the research questions raised in Section 2. Several analyses not raised in the research questions were performed when appropriate for comparison to the Rogers et al. (2009) paper.

\subsection{Do Forecast Revisions Affect Implied Volatility?}

We first examine whether forecast revisions, on average, create or resolve uncertainty. Table 4 (Hypothesis 1A) reports changes in implied volatilities for options with various times to expiration during the seven days centered on forecast revision dates. Average changes for all times to expiration are positive, indicating that analyst forecast revisions, like management forecasts (Rogers et al. (2009)) exacerbate uncertainty about firm value. What is interesting, however, is that the magnitude of changes in implied volatilities is much greater for management forecasts 
(average $=1.98 \%)$ than for analyst forecasts (average $=0.10 \%$ from Table 4$)$. It would appear that management forecasts have a much greater market impact than analyst forecasts.

This may be explained by the following argument. First, management has better information than analysts (as a group) about the prospects for the firm even though it may have less credibility with investors (Kothari et al. (2009)). How that trades off in the impact on risk measures is an empirical question. Second, each firm with exchange traded options has an average of 15 analysts (all forecasting the same thing) and only one management team. Furthermore, the sheer number of analyst forecasts $(\sim 176,000)$ in our study is greater by almost an order of magnitude than the number of management forecasts $(\sim 21,600)$ in Rogers et al. (2009). This suggests that the effect of a single analyst forecast revision on implied volatility may be substantially smaller than a management forecast. Further, unlike the management forecasts, analyst forecasts are a two-dimensional information transfer in that the market must process the mean and the variance for a given income forecast. Therefore, it is plausible that the impact of just the mean of analysts' forecasts may have a lesser impact.

In Table 5 (Hypothesis 1B), we examine whether larger forecast revisions result in larger changes in implied volatilities. We document a monotonic increase in absolute changes in implied volatilities across quintiles sorted by absolute magnitude of forecast revisions. In fact, across different times to expiration, the average change in implied volatility for the smallest (largest) quintile of forecast revisions is $0.42 \%(11.08 \%)$.

Table 6 (Hypothesis 2) examines the effect of one important forecast characteristic, i.e., the news (good vs bad) of the forecast revision, on changes in implied volatilities. Consistent with Rogers et al. (2009) and Kothari et al. (2009), we find that good (bad) news forecasts are associated 
with decreases (increases) in uncertainty. Specifically, the average decrease (increase) in implied volatility for good (bad) news forecasts is $-0.14 \%(+0.29 \%)$.

Table 7 (Hypothesis $3 A$ ) examines whether changes in forecast dispersion are related to changes in implied volatilities. The sample is divided into dispersion decreasing and dispersion increasing groups at the forecast revision dates. While implied volatilities on average, increase for both groups, the increase is significantly smaller for the dispersion decreasing subset $(0.11 \%)$ than for the dispersion increasing subset $(0.24 \%)$. We conclude from this univariate test that forecast dispersion may be a reasonable proxy for uncertainty about firm value. We note, without explanation, that the difference in implied volatility for the two groups is not statistically significant for 30 day options.

The prior two tables indicate that both the content of the forecast revision (news) and the change in dispersion resulting from the forecast revision are systematically related to changes in implied volatilities during the days surrounding a forecast revision. This suggests that further splitting the sample into good news, dispersion decreasing forecasts and bad news, dispersion increasing forecasts may result in more pronounced differences in implied volatilities. Table 8 (Hypothesis $3 B$ ) reports that the decrease in implied volatility for the first group is $-0.22 \%$ and the increase in implied volatility for the second group is $+0.15 \%$. The difference in implied volatilities is $0.37 \%$ which is bigger than difference between dispersion decreasing/increasing groups (Table 6: $0.24 \%$ and $0.11 \%$ ) and also smaller that the difference between the good/bad news groups (Table 7: $0.29 \%$ and $-0.14 \%$ ). This may be due to the fact that news and changes in dispersion are correlated and not independent.

We next examine the effect of the forecast, firm and market characteristics on changes in implied volatilities in a multivariate regression format. Recall that in the univariate analyses, the 
absolute magnitude of the forecast revision, the news (sign) of the forecast revision, and the change in dispersion of forecasts on the days surrounding a forecast revision were all individually associated with changes in implied volatilities. In this analysis we begin with the news and the absolute magnitude of the forecast revision as explanatory variables for changes in implied volatilities and then sequentially add the change in dispersion of forecasts and two control variables (number of analysts as a proxy for the richness of the information environment and the change in the ISD Index (market-wide movements in implied volatilities).

Table 9 (see the regression including all variables) documents that the sign of the news (good vs bad), the absolute magnitude of the news (magnitude of the forecast revision) and the change in dispersion of analysts' forecasts are all statistically significant even when controlling for the richness of the information environment (number of analysts and the average frequency of analyst forecast revisions) and the market wide movements in implied volatility (log of ISD index). This is true for option expirations dates of 30,60 and 91 days. We infer from Tables 4 through 9 that implied market volatility responds systematically to the release of analyst forecast revisions.

\subsection{Do Changes in Implied Volatility Affect Forecast Revisions?}

This section examines whether analysts incorporate the observable information about changes in implied volatilities into their forecasts. Refer to Figure 2 and consider the following example. Firm XYZ has 10 analysts following it. One analyst issues a forecast revision on March 14 resulting in a consensus forecast of $\$ 3.50$ per share. On April 22 (39 days later), another analyst issues a forecast revision that moves the consensus to $\$ 3.55$ per share (good news). The second analyst has the changes in implied volatilities over that 39 day period available to him/her and can incorporate that information into the forecast revision. For example, if implied volatilities had 
declined (increased) during that 39 day period, the analyst might be more likely to issue a good (bad) news forecast revision.

Table 10 uses a logit regression where the sign of the news (good/bad) is the dependent variable and the change in implied volatility since the prior forecast revision is the primary independent variable. The analysis is conducted for 30,60, and 91 day options (panels $\mathrm{A}$, B, and C). The regression in the left part of each panel has just the change in implied volatility as the explanatory variable, while the regression in the right part of each panel adds the log of the number of analysts and the log of the change in market wide volatility as control variables. The coefficient on changes in implied volatility is significant at conventional levels for 30 day options. This is true for the univariate regression as well as the regression that includes the control variables. Coefficients in the 60 and 91 day options are not significant (with the exception of univariate regression for 60 day options where $\mathrm{p}=.048$ ). Coefficients across the three option durations are very consistent in magnitude, ranging from -0.0934 to -0.1053 across the six regressions. Given the large sample size and the borderline statistical significance, we conclude that analysts do not put much weight on changes in implied volatility in their decision to issue an upward or downward forecast revision.

\subsection{Are Changes in Dispersion of Forecasts Correlated with Changes in Implied Volatility?}

Accounting researchers have long used the dispersion of analysts' forecasts as a proxy for uncertainty about firm value. The availability of ISD's allows us to test whether there is agreement between the two metrics. Table 11 (Hypothesis 4), therefore, examines whether changes in forecast dispersion are correlated with changes in implied volatilities during the period between forecast revisions. Three regressions are performed with changes in dispersion as the dependent variable and (1) just changes in implied volatility as the independent variable, (2) the same 
regression as in (1) with the sign of the news and the absolute magnitude of the forecast revision included as control variables, and (3) the same regression as in (2) plus the log of the number of analysts and the log of the ISD index added as control variables. In all three regressions, the parameter on the change in implied volatility is stable and significant. We conclude that changes in dispersion of analyst forecasts is a good proxy for market based changes in uncertainty about firm value.

\section{Conclusions}

We ask three questions in this study. First, does the market's perception of uncertainty about firm value (proxied by implied volatilities derived from exchange traded options) change as a result of analysts' forecast revisions? We find support for this proposition using an event study methodology during the seven days surrounding and including each forecast revision date. Like previous studies, we find that (1) forecast revisions, on average, increase uncertainty, (2) larger

forecast revisions (absolute value) result in larger changes in uncertainty, (3) good (bad) news forecast revisions resolve (exacerbate) uncertainty, and (4) dispersion decreasing (increasing) forecast revisions resolve (exacerbate) uncertainty. Univariate test and multivariate regressions confirm these results.

Second, we document that analysts do not appear to use changes in implied volatilities between forecast revisions to nudge their forecasts toward good or bad news. The quality off analysts' forecasts may be improved by the use of the information contained in the volatility of exchange traded options. However, capital markets research using ISD's is still relatively new. Useful information for market participants is limited at this time, but may be forthcoming in the future. 
Third, we find that changes in forecast dispersion are a reasonable proxy for changes in implied volatility. This is tested in a multivariate regression with multiple control variables. 


\section{References}

Adut, Davit and Sen, Pradyot K. and Sinha, Praveen, Properties of the Variance of Analysts' Forecast of Earnings in Good-News and Bad-News Environments: Theory, Evidence and Usefulness, (2008). SSRN: http://ssrn.com/abstract=1270682

Avramov, Doron; Chordia, Tarun; Jostova, Gergana; Philipov, Alexander. Dispersion in Analysts' Earnings Forecasts and Credit Rating, Journal of Financial Economics 91.1 (Jan 2009): 83-101.

Ball, Ray; Kothari, S P. Non-stationary Expected Returns: Implications for Tests of Market Efficiency and Serial Correlation in Returns, Journal of Financial Economics 25.1 (Nov 1989): 51-74.

Barron, Orie E; Stuerke, Pamela S. Dispersion in Analysts' Earnings Forecasts as a Measure of Uncertainty, Journal of Accounting, Auditing and Finance 13.3 (Jul 1998): 245-270.

Barron, Orie E; Kim, Oliver; Lim, Steve C; Stevens, Douglas E. Using Analysts' Forecasts to Measure Properties of Analysts' Information Environment, Accounting Review 73.4 (Oct 1998): 421-433.

Billings, Mary Brooke; Jennings, Robert; Lev, Baruch, On Guidance and Volatility, Journal of Accounting and Economics, 60 (2015): 161-180.

Brown, Lawrence; Call, Andrew; Clement, Michael, and Sharp, Nathan, Inside the "Black Box" of Sell side Financial Analysts, Journal of Accounting Research, 53 (1) (Mar 2015): 1-47.

Brown, Lawrence; Caylor, Marcus, Corporate Governance and Firm Valuation. Journal of Accounting and Public Policy 25.4 (Jul/Aug 2006): 409-434.

Diamond, Douglas W; Verrecchia, Robert E. Disclosure, Liquidity, and the Cost of Capital, Journal of Finance 46.4 (Sep 1991): 1325-1359.

Easley, David; O'Hara, Maureen. Information and the Cost of Capital, Journal of Finance 59.4 (Aug 2004): 1553-1583.

Healy, Paul M; Palepu, Krishna G. Information Asymmetry, Corporate Disclosure, and the Capital Markets: A Review of the Empirical Disclosure Literature, Journal of Accounting and Economics 31.1-3 (Sep 2001): 405-440.

Imhoff, Eugene A, Jr; Lobo, Gerald J. The Effect of Ex Ante Earnings Uncertainty on Earnings Response Coefficients, Accounting Review 67.2 (Apr 1992): 427-439.

Kothari, S P. Capital Markets Research in Accounting, Journal of Accounting and Economics 31.1-3 (Sep 2001): 105-231. 
Kothari, S P; Li, Xu; Short, James E. The Effect of Disclosures by Management, Analysts, and Business Press on Cost of Capital, Return Volatility, and Analyst Forecasts: A Study Using Content Analysis, Accounting Review 84.5 (Sep 2009): 1639-1670.

Liu, Michelle; Wysocki, Peter D. Cross-Sectional Determinants of Information Quality Proxies and Cost of Capital Measures, SSRN Working Paper Series, Jan 2008.

Rees, Lynn, Twedt, Brady, The stock price effects from downward earnings guidance versus beating analysts' forecasts: which effect dominates?, Accounting and Business Research (June 2011) Vol. 41, No. 2, 95-118

Rogers, Jonathan L; Skinner, Douglas J; Van Buskirk, Andrew. Earnings guidance and market uncertainty, Journal of Accounting \& Economics 48.1 (Oct 2009): 90.

Tang, Michel, Zarowin, Paul: Zhang, Li, How do Analysts Interpret Management Range Forecasts?, working paper, (May 2014).

Yoo, Chueng-Yuel, Pae, Jinhan, Do Analysts Strategically Employ Cash Flow Forecast Revisions to Offset Negative Earnings Forecast Revisions?, European Accounting Review (2017), Vol. 26, No. 2, 193-214 
Figure 1

Sample Timeline for Changes in Implied Volatiliy Around Forecast Revisions

\begin{tabular}{llll}
$14-\mathrm{Mar}$ & 17-Apr & $22-\mathrm{Apr}$ & $25-\mathrm{Apr}$ \\
\hline $\mathrm{AF}_{\text {priordate }}$ & & $\mathrm{AF}_{\text {revdate }}$ & \\
$\mathrm{DISP}_{\text {priordate }}$ & $\sigma_{\text {revdate - 3 }}$ & $\mathrm{DISP}_{\text {revdate }}$ & $\sigma_{\text {revdate }+3}$
\end{tabular}

$\mathrm{AF}_{\text {priordate }}=$ mean of all analysts' forecasts following the firm on March 14

$\mathrm{AF}_{\text {revdate }}=$ mean of all analysts' forecasts following the firm on April 22

$\sigma_{\text {revdate - } 3}=$ ISD for 30, 60, $91 \ldots$ day options on April 17 (3 trading days before the forecast revision)

$\sigma_{\text {revdate }+3}=$ ISD for $30,60,91 \ldots$ day options on April 25 (3 trading days after the forecast revision)

$\mathrm{DISP}_{\text {revdate }}=$ standard deviation of analysts' forecasts on forecast revision date scaled by $\mathrm{AF}_{\text {revdate }}$

$\mathrm{DISP}_{\text {priordate }}=$ standard deviation of analysts' forecasts on forecast revision date scaled by $\mathrm{AF}_{\text {priordate }}$

Change in analysts' forecasts $=\left(\mathrm{AF}_{\text {revdate }}-\mathrm{AF}_{\text {priordate }}\right) /$ Price $_{\text {priordate }}$

Change in implied volatility $=\ln \left(\sigma_{\text {revdate }+3} / \sigma_{\text {revdate }-3}\right)$

Change in dispersion of forecasts $=$ DISP $_{\text {revdate }}-$ DISP $_{\text {priordate }}$ 


\section{Figure 2}

Sample Timeline for Changes in Implied Volatiliy Between Forecast Revisions

\begin{tabular}{lcc}
$14-$ Mar & 17-Apr & 22-Apr \\
\hline $\mathrm{AF}_{\text {priordate }}$ & & $\mathrm{AF}_{\text {revdate }}$ \\
$\sigma_{\text {priordate }}$ & $\sigma_{\text {revdate - 3 }}$ & $\sigma_{\text {revdate }}$ \\
DISP $_{\text {priordate }}$ & & $\mathrm{DISP}_{\text {revdate }}$
\end{tabular}

$\mathrm{AF}_{\text {priordate }}=$ mean of all analysts' forecasts following the firm on March 14

$\mathrm{AF}_{\text {revdate }}=$ mean of all analysts' forecasts following the firm on April 22

$\sigma_{\text {priordate }}=$ ISD for $30,60,91 \ldots$ day options on March 14

$\sigma_{\text {revdate - } 3}=$ ISD for $30,60,91 \ldots$ day options on April 17 (3 trading days prior to the forecast revision)

$\mathrm{DISP}_{\text {revdate }}=$ standard deviation of analysts' forecasts on forecast revision date scaled by $\mathrm{AF}_{\text {revdate }}$

$\mathrm{DISP}_{\text {priordate }}=$ standard deviation of analysts' forecasts on forecast revision date scaled by $\mathrm{AF}_{\text {priordate }}$

Change in analysts' forecasts $=\left(\mathrm{AF}_{\text {revdate }}-\mathrm{AF}_{\text {priordate }}\right) /$ Price priordate

Change in implied volatility $=\ln \left(\sigma_{\text {revdate }-3} / \sigma_{\text {priordate }}\right)$

Change in dispersion of forecasts $=$ DISP $_{\text {revdate }}-\mathrm{DISP}_{\text {priordate }}$ 
Table 1

Sample Availability and Screening Procedures*

\begin{tabular}{|c|c|}
\hline & \#Observations \\
\hline Initial sample from IBES & 181,662 \\
\hline Less Missing COMPUSTAT data & $(1,487)$ \\
\hline Less Missing CRSP data & $(4,343)$ \\
\hline Remaining firm year observations & 175,832 \\
\hline
\end{tabular}

*30 day options

Table 2

Number of Forecast Revision Dates

\begin{tabular}{|c|c|}
\hline Option Duration & \# Observations \\
\hline & \\
\hline 30 days & 175,832 \\
\hline 60 days & 176,125 \\
\hline 91 days & 176,633 \\
\hline 122 days & 176,416 \\
\hline 152 days & 172,900 \\
\hline 182 days & 131,316 \\
\hline 273 days & 67,787 \\
\hline 365 days & 67,501 \\
\hline 547 days & 66,565 \\
\hline 730 days & 38,680 \\
\hline
\end{tabular}


Table 3

Changes in Implied Volatilities on Forecast Revision Dates

\begin{tabular}{|l|c|c|c|c|c|}
\hline $\begin{array}{l}\text { Option } \\
\text { Duration }\end{array}$ & \#Observations & Mean & $\begin{array}{c}25^{\text {th }} \\
\text { Percentile }\end{array}$ & Median & $\begin{array}{c}75^{\text {th }} \\
\text { Percentile }\end{array}$ \\
\hline 30 days & 175,832 & $0.10 \%$ & $-4.96 \%$ & $-0.09 \%$ & $4.90 \%$ \\
\hline 60 days & 176,125 & $0.11 \%$ & $-3.87 \%$ & $-0.22 \%$ & $3.61 \%$ \\
\hline 91 days & 176,633 & $0.17 \%$ & $-3.05 \%$ & $-0.17 \%$ & $2.86 \%$ \\
\hline 122 days & 176,416 & $0.16 \%$ & $-2.70 \%$ & $-0.17 \%$ & $2.53 \%$ \\
\hline 152 days & 172,900 & $0.14 \%$ & $-2.50 \%$ & $-0.19 \%$ & $2.28 \%$ \\
\hline 182 days & 131,316 & $0.15 \%$ & $-2.33 \%$ & $0.15 \%$ & $2.16 \%$ \\
\hline 273 days & 67,787 & $0.04 \%$ & $-2.27 \%$ & $-0.18 \%$ & $2.03 \%$ \\
\hline 365 days & 67,501 & $0.03 \%$ & $-1.92 \%$ & $-0.12 \%$ & $1.73 \%$ \\
\hline 547 days & 66,565 & $0.02 \%$ & $-1.65 \%$ & $-0.10 \%$ & $1.44 \%$ \\
\hline 730 days & 38,680 & $0.06 \%$ & $-1.43 \%$ & $-0.07 \%$ & $1.27 \%$ \\
\hline News & 183,194 & 0.446 & 0.000 & 0.000 & 1.000 \\
\hline AbsNews & 183,194 & 0.031 & 0.003 & 0.008 & 0.025 \\
\hline$\Delta$ Disp & 183,194 & 0.163 & 0.029 & 0.069 & 0.176 \\
\hline AnFollowing & 183,194 & 14.705 & 8.000 & 13.000 & 20.000 \\
\hline ISD_Index & 183,194 & 1.003 & 0.928 & 0.991 & 1.065 \\
\hline MVE & 182,708 & 14,158 & 10,833 & 3,395 & 10,943 \\
\hline Leverage & 182,651 & 0.2103 & 0.0495 & 0.1798 & 0.3174 \\
\hline BM ratio & 182,680 & 10.1338 & 0.2132 & 0.3655 & 0.5464 \\
\hline Frequency & 183,194 & 5.9162 & 4.2500 & 5.5111 & 7.1776 \\
\hline & & & & & \\
\hline
\end{tabular}

This table provides descriptive statistics for changes in implied volatility around forecast revision dates by quartiles. The absolute change in mean analysts' forecasts is scaled by the stock price on the prior revision date. Implied Volatility $[30,60,91,122,152,273,365,547,730]$ is the $\ln \left(\sigma_{\text {Revdate }+3} / \sigma_{\text {Revdate-3) }}\right.$ which represents the natural logarithm of the ratio of the post-forecast Implied Volatility (three trading days after the analysts' forecast revision) to the pre-forecast Implied Volatility (three trading days before the analysts' forecast revision). News is 1 if mean analyst forecast is greater than the previous forecast and zero otherwise. AbsNews is the absolute value of the magnitude of the difference between the mean analyst forecast and the previous mean analyst forecast scaled by price. $\Delta$ Disp is the change in dispersion between the revision date and the previous revision date. AnFollowing is the natural logarithm of the number of analysts following a firm. ISD_Index is the natural logarithm of the ratio of the level of the Chicago Board Options Exchange Volatility Index on the post- forecast date scaled by the value of the index on the pre-forecast. Frequency is the average revision frequency of analysts who follow firm $i$ in year $t$. $M V E$ is the market value of equity prior to forecast issuance. Leverage is the ratio of long term debt to total assets. BM ratio is the ratio of the firm's shareholders' equity to market value prior to the forecast issuance. 
Table 4

Changes in Implied Volatility Around Forecast Revision Dates

\begin{tabular}{cccc}
\hline $\begin{array}{c}\text { Option } \\
\text { Duration (days) }\end{array}$ & $\mathbf{N}$ & $\boldsymbol{l n}\left(\boldsymbol{\sigma}_{\text {revdate }+\mathbf{3} / \boldsymbol{\sigma}_{\text {revdate }-\mathbf{3})}}\right.$ & t-statistic \\
\hline $\mathbf{3 0}$ & 175,832 & 0.0010 & 3.69 \\
$\mathbf{6 0}$ & 176,125 & 0.0011 & 5.54 \\
$\mathbf{9 1}$ & 176,633 & 0.0017 & 9.70 \\
$\mathbf{1 2 2}$ & 176,416 & 0.0016 & 9.88 \\
$\mathbf{1 5 2}$ & 172,900 & 0.0014 & 9.09 \\
$\mathbf{1 8 2}$ & 131,316 & 0.0015 & 9.12 \\
$\mathbf{2 7 3}$ & 67,787 & 0.0004 & 2.16 \\
$\mathbf{3 6 5}$ & 67,501 & 0.0003 & 1.66 \\
$\mathbf{5 4 7}$ & 66,565 & 0.0002 & 1.33 \\
$\mathbf{7 3 0}$ & 38,680 & 0.0006 & 2.65 \\
\hline Average & & 0.0010 & \\
\hline
\end{tabular}

This table provides descriptive statistics for changes in implied volatility around forecast revision dates. Implied_Volatility_[30,60,91,122,152,273, 365,547, 730] is the ln $\left(\sigma_{\text {Revdate }+3}\right.$ $/ \sigma_{\text {Revdate-3) }}$ ) which represents the natural logarithm of the ratio of the post-forecast Implied Volatility (three trading days after the analysts' forecast revision) to the pre-forecast Implied Volatility (three trading days before the analysts' forecast revision). 
Table 5

Absolute Changes in Implied Volatility and Forecast Revisions Around Forecast Revision Dates

\begin{tabular}{|c|c|c|c|c|c|c|}
\hline $\begin{array}{c}\text { Option } \\
\text { Duration (days) }\end{array}$ & $\mathbf{N}$ & Q1* & Q2 & Q3 & Q4 & Q5* \\
\hline 30 & 175,832 & 0.0081 & 0.0261 & 0.0498 & 0.0864 & 0.1955 \\
\hline 60 & 176,125 & 0.0062 & 0.0200 & 0.0379 & 0.0659 & 0.1528 \\
\hline 91 & 176,633 & 0.0048 & 0.0155 & 0.0299 & 0.0528 & 0.1280 \\
\hline 122 & 176,416 & 0.0042 & 0.0136 & 0.0265 & 0.0474 & 0.1175 \\
\hline 152 & 172,900 & 0.0038 & 0.0124 & 0.0243 & 0.0437 & 0.1106 \\
\hline 182 & 131,316 & 0.0036 & 0.0117 & 0.0228 & 0.0408 & 0.1031 \\
\hline 273 & 67,787 & 0.0036 & 0.0116 & 0.0219 & 0.0373 & 0.0867 \\
\hline 365 & 67,501 & 0.0030 & 0.0097 & 0.0185 & 0.0323 & 0.0774 \\
\hline 547 & 66,565 & 0.0024 & 0.0080 & 0.0157 & 0.0279 & 0.0696 \\
\hline 730 & 38,680 & 0.0020 & 0.0069 & 0.0137 & 0.0249 & 0.0669 \\
\hline Average & & 0.0042 & 0.0135 & 0.0261 & 0.0459 & 0.1108 \\
\hline
\end{tabular}

This table provides descriptive statistics for changes in implied volatility around forecast revision dates by quintiles. The quintiles are based on the absolute change in mean analysts' forecasts between the revision date and the prior revision date. The absolute change in mean analysts' forecasts is scaled by the stock price on the prior revision date.

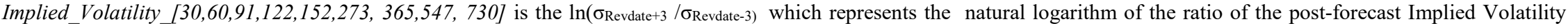
(three trading days after the analysts' forecast revision) to the pre-forecast Implied Volatility (three trading days before the analysts' forecast revision). 
Table 6

Changes in Implied Volatility Around Forecast Revision Dates: Dispersion Increasing vs. Dispersion Decreasing

\begin{tabular}{|c|c|c|c|c|c|}
\hline \multirow[b]{2}{*}{$\begin{array}{c}\text { Option } \\
\text { Duration }\end{array}$} & \multicolumn{2}{|c|}{ Dispersion Decreasing } & \multicolumn{2}{|c|}{ Dispersion Increasing } & \multirow{2}{*}{$\begin{array}{l}\text { t-statistic } \\
\text { Difference }\end{array}$} \\
\hline & $\mathrm{N}$ & $\ln \left(\sigma_{\text {revdate }}+3 / \sigma_{\text {revdate }-3}\right)$ & $\mathrm{N}$ & $\ln \left(\sigma_{\text {revdate }+3} / \sigma_{\text {revdate }-3}\right)$ & \\
\hline 30 & 94,949 & 0.0026 & 75,660 & 0.0023 & 0.53 \\
\hline 60 & 94,732 & 0.0017 & 75,438 & 0.0028 & -2.41 \\
\hline 91 & 94,489 & 0.0017 & 75,225 & 0.0035 & -4.90 \\
\hline 122 & 94,232 & 0.0015 & 74,990 & 0.0035 & -5.79 \\
\hline 152 & 92,100 & 0.0012 & 73,249 & 0.0033 & -6.27 \\
\hline 182 & 70,564 & 0.0013 & 55,335 & 0.0033 & -5.82 \\
\hline 273 & 37,809 & 0.0003 & 28,155 & 0.0018 & -3.78 \\
\hline 365 & 37,613 & 0.0000 & 28,023 & 0.0014 & -3.72 \\
\hline 547 & 37,089 & 0.0000 & 27,514 & 0.0012 & -3.27 \\
\hline 730 & 22,247 & 0.0003 & 16,490 & 0.0013 & -2.30 \\
\hline Average & & 0.0011 & & 0.0024 & \\
\hline
\end{tabular}

This table provides descriptive statistics for changes in implied volatility around forecast revision dates partitioned on dispersion around analysts' forecasts. . A forecast is coded dispersion decreasing if the standard deviation of the mean analysts' forecast declines from the prior revision date. A forecast is coded dispersion increasing if the standard deviation of the mean analysts' forecast increases from the prior revision date. Implied_Volatility_[30,60,91,122,152,273, 365,547, 730] is the ln $(\sigma$ Revdate $+3 / \sigma$ Revdate-3) which represents the natural logarithm of the ratio of the post-forecast Implied Volatility (three trading days after the analysts' forecast revision) to the pre-forecast Implied Volatility (three trading days before the analysts' forecast revision) 
Table 7

Changes in Implied Volatility Around Forecast Revision Dates: Good vs. Bad News

\begin{tabular}{ccccc}
\hline & \multicolumn{2}{c}{ Good News Forecast Revisions } & \multicolumn{2}{c}{ Bad News Forecast Revisions } \\
\hline $\begin{array}{c}\text { Option } \\
\text { Duration (days) }\end{array}$ & $\mathrm{N}$ & $\ln \left(\sigma_{\text {revdate }+3} / \sigma_{\text {revdate }-3)}\right.$ & $\mathrm{N}$ & $\ln \left(\sigma_{\text {revdate }+3} / \sigma_{\text {revdate }-3)}\right.$ \\
$\mathbf{3 0}$ & 79,170 & $(0.0016)$ & 96,662 & 0.0031 \\
$\mathbf{6 0}$ & 79,211 & $(0.0016)$ & 96,914 & 0.0034 \\
$\mathbf{9 1}$ & 79,316 & $(0.0012)$ & 97,317 & 0.0040 \\
$\mathbf{1 2 2}$ & 79,206 & $(0.0012)$ & 97,210 & 0.0039 \\
$\mathbf{1 5 2}$ & 77,743 & $(0.0012)$ & 95,157 & 0.0036 \\
$\mathbf{1 8 2}$ & 59,219 & $(0.0010)$ & 72,097 & 0.0036 \\
$\mathbf{2 7 3}$ & 31,249 & $(0.0014)$ & 36,538 & 0.0020 \\
$\mathbf{3 6 5}$ & 31,076 & $(0.0013)$ & 36,425 & 16.06 \\
$\mathbf{5 4 7}$ & 30,687 & $(0.0013)$ & 35,878 & 0.0017 \\
$\mathbf{7 3 0}$ & 15,500 & $(0.0015)$ & 21,180 & 0.0015 \\
Average & & $(0.0014)$ & & 8.97 \\
\hline
\end{tabular}

This table provides descriptive statistics for changes in implied volatility around forecast revision dates partitioned on type of news. A forecast is coded good news if the analysts' forecast exceeds the analysts' forecast on the previous revision date. A forecast is coded bad news if the analysts' forecast on the previous revision date exceeds the current analysts' forecast. Implied Volatility [30,60,91,122,152,273, 365,547, 730] is the $\ln (\sigma$ Revdate $+3 / \sigma$ Revdate-3) which represents the natural logarithm of the ratio of the post-forecast Implied Volatility (three trading days after the analysts' forecast revision) to the pre-forecast Implied Volatility (three trading days before the analysts' forecast revision). 
Table 8

Changes in Implied Volatility Around Forecast Revision Dates

Good News and Dispersion Decreasing vs. Bad News and Dispersion Increasing

\begin{tabular}{|c|c|c|c|c|c|}
\hline \multirow[b]{2}{*}{$\begin{array}{c}\text { Option } \\
\text { Duration (days) }\end{array}$} & \multicolumn{2}{|c|}{$\begin{array}{c}\text { Good News and Dispersion } \\
\text { Decreasing }\end{array}$} & \multicolumn{2}{|c|}{ Bad News and Dispersion Increasing } & \multirow{2}{*}{$\begin{array}{l}\text { t-statistic } \\
\text { Difference }\end{array}$} \\
\hline & $\mathrm{N}$ & $\ln \left(\sigma_{\text {revdate }}+3 / \sigma_{\text {revdate }-3}\right)$ & $\mathrm{N}$ & $\ln \left(\sigma_{\text {revdate }}+3 / \sigma_{\text {revdate }-3}\right)$ & \\
\hline 30 & 34,739 & $(0.0039)$ & 51,773 & 0.0021 & $(5.47)$ \\
\hline 60 & 34,769 & $(0.0032)$ & 51,861 & 0.0019 & $(9.45)$ \\
\hline 91 & 34,810 & $(0.0022)$ & 52,030 & 0.0022 & $(13.48)$ \\
\hline 122 & 34,753 & $(0.0020)$ & 51,958 & 0.0021 & $(14.65)$ \\
\hline 152 & 34,124 & $(0.0019)$ & 50,899 & 0.0017 & (14.99) \\
\hline 182 & 25,691 & $(0.0015)$ & 38,850 & 0.0018 & $(13.40)$ \\
\hline 273 & 13,077 & $(0.0020)$ & 20,395 & 0.0006 & $(8.81)$ \\
\hline 365 & 13,003 & $(0.0017)$ & 20,332 & 0.0006 & $(8.43)$ \\
\hline 547 & 12,833 & $(0.0016)$ & 20,075 & 0.0006 & $(8.33)$ \\
\hline 730 & 7,242 & $(0.0020)$ & 11,941 & 0.0013 & $(7.68)$ \\
\hline Average & & $(0.0022)$ & & 0.0015 & \\
\hline
\end{tabular}

This table provides descriptive statistics for changes in implied volatility around forecast revision dates partitioned on type of news and dispersion. A forecast is coded good news and dispersion decreasing if the analysts' forecast exceeds the analysts' forecast on the previous revision date and the standard deviation of the mean analysts' forecast on the revision date is less than on the previous revision date. A forecast is coded bad news and dispersion increasing if the analysts' forecast on the previous revision date exceeds the current analysts' forecast and the standard deviation of the mean analysts' forecast on the revision date is greater than on the previous revision date. Implied_Volatility_[30,60,91,122,152,273, $365,547,730]$ is the $\ln \left(\sigma_{\text {Revdate }+3} / \sigma_{\text {Revdate-3) }}\right.$ which represents the natural logarithm of the ratio of the post-forecast Implied Volatility (three trading days after the analysts' forecast revision) to the pre-forecast Implied Volatility (three trading days before the analysts' forecast revision). 
Table 9

Multivariate Analysis of Changes in Implied Volatility Around Forecast Revision Dates

\begin{tabular}{|c|c|c|c|c|c|c|}
\hline \multicolumn{7}{|l|}{ Panel A: 30 Day Options } \\
\hline Independent variables & parameter & t-statistic & parameter & t-statistic & parameter & t-statistic \\
\hline Intercept & 0.0045 & 12.19 & 0.0058 & 15.54 & 0.0019 & 4.68 \\
\hline News & $(0.0048)$ & $(8.82)$ & $(0.0046)$ & $(8.38)$ & $(0.0046)$ & $(8.60)$ \\
\hline AbsNews & 0.1257 & 2.39 & 0.2606 & 4.14 & 0.0626 & 3.27 \\
\hline$\Delta$ DISP & & & 0.0064 & 2.16 & 0.0069 & 2.36 \\
\hline An_Following & & & & & $(0.0027)$ & $(4.31)$ \\
\hline ISD_Index & & & & & 0.2012 & 84.08 \\
\hline Ln Frequency & & & & & 0.0030 & 4.11 \\
\hline MVE & & & & & 0.0001 & 0.25 \\
\hline Leverage & & & & & 0.0015 & 1.02 \\
\hline BM ratio & & & & & 0.0000 & 0.92 \\
\hline Number observations & \multicolumn{2}{|c|}{170,609} & \multicolumn{2}{|c|}{162,501} & \multicolumn{2}{|c|}{161,385} \\
\hline Adjusted $\mathbf{R}^{2}$ & \multicolumn{2}{|c|}{$0.05 \%$} & \multicolumn{2}{|c|}{$0.06 \%$} & \multicolumn{2}{|c|}{$4.27 \%$} \\
\hline
\end{tabular}




\begin{tabular}{|c|c|c|c|c|c|c|}
\hline Independent variables & parameter & t-statistic & parameter & t-statistic & parameter & t-statistic \\
\hline Intercept & 0.0043 & 14.75 & 0.0050 & 16.68 & 0.0103 & 6.78 \\
\hline News & $(0.0053)$ & $(12.28)$ & $(0.0053)$ & $(12.02)$ & $(0.0052)$ & $(12.02)$ \\
\hline AbsNews & 0.1826 & 4.31 & 0.2902 & 5.71 & 0.2348 & 4.64 \\
\hline ADISP & & & 0.0065 & 2.72 & 0.0070 & 2.97 \\
\hline An_Following & & & & & $(0.0022)$ & $(4.45)$ \\
\hline ISD_Index & & & & & 0.1527 & 79.39 \\
\hline Ln Frequency & & & & & 0.0020 & 3.36 \\
\hline MVE & & & & & $(0.0002)$ & $(1.04)$ \\
\hline Leverage & & & & & 0.0002 & 0.19 \\
\hline BM ratio & & & & & 0.0000 & 1.41 \\
\hline Number observations & \multicolumn{2}{|c|}{170,170} & \multicolumn{2}{|c|}{162,167} & \multicolumn{2}{|c|}{161,017} \\
\hline Adjusted $\mathbf{R}^{2}$ & \multicolumn{2}{|c|}{$0.10 \%$} & \multicolumn{2}{|c|}{$0.12 \%$} & \multicolumn{2}{|c|}{$3.91 \%$} \\
\hline
\end{tabular}




\begin{tabular}{|c|c|c|c|c|c|c|}
\hline Independent variables & parameter & t-statistic & parameter & t-statistic & parameter & t-statistic \\
\hline Intercept & 0.0048 & 19.21 & 0.0051 & 20.42 & 0.0104 & 8.15 \\
\hline News & $(0.0057)$ & $(15.56)$ & $(0.0057)$ & $(15.23)$ & $(0.0056)$ & $(15.24)$ \\
\hline AbsNews & 0.2415 & 6.77 & 0.3336 & 7.77 & 0.2902 & 6.79 \\
\hline ADISP & & & 0.0076 & 3.79 & 0.0080 & 4.05 \\
\hline An_Following & & & & & $(0.0014)$ & $(3.26)$ \\
\hline ISD_Index & & & & & 0.1295 & 79.93 \\
\hline Ln Frequency & & & & & 0.0012 & 2.45 \\
\hline MVE & & & & & $(0.0003)$ & $(2.23)$ \\
\hline Leverage & & & & & $(0.0005)$ & $(0.48)$ \\
\hline BM ratio & & & & & $(0.0000)$ & $(2.66)$ \\
\hline Number observations & \multicolumn{2}{|c|}{169,714} & \multicolumn{2}{|c|}{161,730} & \multicolumn{2}{|c|}{160,627} \\
\hline Adjusted $\mathbf{R}^{2}$ & \multicolumn{2}{|c|}{$0.17 \%$} & \multicolumn{2}{|c|}{$0.20 \%$} & \multicolumn{2}{|c|}{$4.04 \%$} \\
\hline
\end{tabular}

*This table reports the multivariate regression results for the change in implied volatility surrounding an analyst's forecast. The sample includes analysts' forecasts made between 1996 and 2006. The dependent variable in each panel is Implied_Volatility_[30,60,91] which is measured as the $\ln \left(\sigma_{\text {Revdate } 3} / \sigma_{\text {Revdate-3) }}\right)$ which represents the natural logarithm of the ratio of the post-forecast Implied Volatility (three trading days after the analysts' forecast revision) to the pre-forecast Implied Volatility (three trading days before the analysts' forecast revision).

News is 1 if mean analyst forecast is greater than the previous forecast and zero otherwise. AbsNews is the absolute value of the magnitude of the difference between the mean analyst forecast and the previous mean analyst forecast scaled by price. $\Delta$ Disp is the change in dispersion between the revision date and the previous revision date.

An_Following is the natural logarithm of the number of analysts following a firm. ISD_Index is the natural logarithm of the ratio of the level of the Chicago Board Options Exchange Volatility Index on the post- forecast date scaled by the value of the index on the pre-forecast.

***,**,* indicate that the statistic is statistically different from 0 at the $1 \%, 5 \%$ and $10 \%$ significance level (two tailed).

Table 10 
Multivariate Analysis of Changes in Implied Volatility and News in Forecast Revisions

\begin{tabular}{|c|c|c|c|c|c|c|}
\hline \multicolumn{7}{|l|}{ Panel A: 30 Day Options } \\
\hline Independent variables & Parameter & Wald Chi-Square & $\operatorname{Pr}>$ ChiSq & Parameter & Wald Chi-Square & $\operatorname{Pr}>$ ChiSq \\
\hline Intercept & $(0.2113)$ & 1829.56 & 0.000 & $(0.2941)$ & 237.59 & 0.000 \\
\hline $\ln \left(\sigma_{\text {revdate }} / \sigma_{\text {priordate }}\right)$ & $(0.1004)$ & 5.18 & 0.023 & $(0.0953)$ & 4.50 & 0.034 \\
\hline An_Following & & & & 0.0321 & 21.25 & 0.000 \\
\hline ISD_Index & & & & 0.0730 & 2.65 & 0.104 \\
\hline Number observations & \multicolumn{2}{|r|}{165,762} & \multicolumn{4}{|c|}{161,815} \\
\hline Log Likelihood & \multicolumn{2}{|r|}{5.19} & \multicolumn{4}{|c|}{28.80} \\
\hline
\end{tabular}

Panel B: 60 Day Options

\begin{tabular}{|c|c|c|c|c|c|c|}
\hline Independent variables & Parameter & Wald Chi-Square & $\operatorname{Pr}>$ ChiSq & Parameter & Wald Chi-Square & $\operatorname{Pr}>$ ChiSq \\
\hline Intercept & $(0.2133)$ & $1,864.670$ & 0.000 & $(0.2955)$ & 239.783 & 0.000 \\
\hline $\ln \left(\sigma_{\text {revdate }} / \sigma_{\text {priordate }}\right)$ & $(0.1053)$ & 3.916 & 0.048 & $(0.0971)$ & 3.214 & 0.073 \\
\hline An_Following & & & & 0.0319 & 20.962 & 0.000 \\
\hline ISD_Index & & & & 0.0749 & 2.794 & 0.095 \\
\hline Number observations & \multicolumn{2}{|c|}{165,868} & \multicolumn{4}{|c|}{161,900} \\
\hline Log Likelihood & \multicolumn{2}{|c|}{3.92} & \multicolumn{4}{|c|}{27.33} \\
\hline
\end{tabular}


Panel C: 91 Day Options

\begin{tabular}{|c|c|c|c|c|c|c|}
\hline Independent variables & Parameter & Wald Chi-Square & $\operatorname{Pr}>$ ChiSq & Parameter & Wald Chi-Square & $\operatorname{Pr}>$ ChiSq \\
\hline Intercept & $(0.2159)$ & $1,912.14$ & 0.000 & $(0.2999)$ & 247.70 & 0.000 \\
\hline $\ln \left(\sigma_{\text {revdate }} / \sigma_{\text {priordate }}\right)$ & $(0.1007)$ & 2.77 & 0.096 & $(0.0934)$ & 2.30 & 0.130 \\
\hline An_Following & & & & 0.0326 & 21.93 & 0.000 \\
\hline ISD_Index & & & & 0.0736 & 2.70 & 0.100 \\
\hline Number observations & & 166,100 & \multicolumn{4}{|c|}{162,109} \\
\hline Log Likelihood & \multicolumn{2}{|r|}{2.78} & \multicolumn{4}{|c|}{27.26} \\
\hline
\end{tabular}

*This table reports the logit regression results for the change in news surrounding an analyst's forecast. The sample includes analysts' forecasts made between 1996 and 2006. The dependent variable in each panel is News which is measured as 1 if the mean analyst forecast is greater than the previous forecast and zero otherwise. The ln $(\sigma$ Revdate $+3 / \sigma$ Revdate- 3 ) represents the natural logarithm of the ratio of the post-forecast Implied Volatility (3 trading days after the analysts' forecasts) to the pre-forecast Implied Volatility ( 3 trading days before the analysts' forecasts). An_Following is the natural logarithm of the number of analysts following a firm. ISD_Index is the natural logarithm of the ratio of the level of the Chicago Board Options Exchange Volatility Index on the post- forecast date scaled by the value of the index on the pre-forecast.

$* * *, * *, *$ indicate that the statistic is statistically different from 0 at the $1 \%, 5 \%$ and $10 \%$ significance level (two tailed). 
Table 11

Multivariate Analysis of Changes in Implied Volatility and Dispersion of Analysts' Forecasts

Regression

$$
\ln \left(\text { DISP }_{\text {revdate }} / \mathrm{DISP} \text { priordate }\right)=\alpha+\beta_{1} \text { signnews }+\beta_{2} \text { absnews }+\beta_{3} \log \# \text { analysts }+\beta_{4} \log I S D i n d e x+\beta_{4} \ln \left(\sigma_{\text {revdate }} / \sigma_{\text {priordate }}\right)
$$

Change in implied volatility $=\ln \left(\sigma_{\text {revdate }} / \sigma_{\text {priordate }}\right)$ as shown in Figure 1 timeline

signnews $=0$ if bad; signnews $=1$ if good

absnews $=\mathrm{ABS}\left[\left(\mathrm{AF}_{\text {revdate }}-\mathrm{AF}_{\text {priordate }}\right) /\right.$ Price $\left._{\text {priordate }}\right]$

$\log \#$ analysts $=$ natural log of number of analysts following the firm

$\operatorname{logISDindex}=$ natural $\log$ of the market change in implied volatility

Panel A: 30 Day Options

\begin{tabular}{|c|c|c|c|c|c|c|}
\hline Independent variables & parameter & t-statistic & parameter & t-statistic & parameter & t-statistic \\
\hline intercept & 0.0427 & 42.22 & 0.0437 & 31.79 & $(0.0747)$ & 18.18 \\
\hline $\ln \left(\sigma_{\text {revdate }} / \sigma_{\text {priordate }}\right)$ & 0.0637 & 3.48 & 0.0622 & 3.43 & 0.0667 & 3.65 \\
\hline signnews & & & $(0.0259)$ & $(12.81)$ & $(0.0258)$ & $(12.71)$ \\
\hline absnews & & & 11.0277 & 46.11 & 13.3606 & 49.83 \\
\hline log\#analysts & & & & & $(0.0122)$ & $(8.51)$ \\
\hline logISDindex & & & & & $(0.0132)$ & $(1.45)$ \\
\hline number observations & \multicolumn{2}{|c|}{155,872} & \multicolumn{2}{|c|}{155,872} & \multicolumn{2}{|c|}{152,274} \\
\hline adjusted $\mathrm{R}^{2}$ & \multicolumn{2}{|c|}{$0.01 \%$} & \multicolumn{2}{|c|}{$1.48 \%$} & \multicolumn{2}{|c|}{$1.88 \%$} \\
\hline
\end{tabular}


Panel B: 60 Day Options

\begin{tabular}{|c|c|c|c|c|c|c|}
\hline Independent variables & parameter & t-statistic & parameter & t-statistic & parameter & t-statistic \\
\hline intercept & 0.0432 & 42.58 & 0.0440 & 31.96 & 0.0748 & 18.19 \\
\hline $\ln \left(\sigma_{\text {revdate }} / \sigma_{\text {priordate }}\right)$ & 0.1300 & 5.51 & 0.1276 & 5.45 & 0.1206 & 5.12 \\
\hline signnews & & & $(0.0266)$ & $(13.11)$ & $(0.0264)$ & $(13.00)$ \\
\hline absnews & & & 11.4803 & 47.85 & 13.9135 & 51.72 \\
\hline log\#analysts & & & & & $(0.0122)$ & $(8.48)$ \\
\hline logISDindex & & & & & $(0.0148)$ & $(1.63)$ \\
\hline number observations & \multicolumn{2}{|c|}{156,172} & \multicolumn{2}{|c|}{156,172} & \multicolumn{2}{|c|}{152,563} \\
\hline adjusted $\mathrm{R}^{2}$ & \multicolumn{2}{|c|}{$0.02 \%$} & \multicolumn{2}{|c|}{$1.60 \%$} & \multicolumn{2}{|c|}{$2.02 \%$} \\
\hline
\end{tabular}

Panel C: 91 Day Options

\begin{tabular}{|c|c|c|c|c|c|c|}
\hline Independent variables & parameter & t-statistic & parameter & t-statistic & parameter & t-statistic \\
\hline intercept & 0.0435 & 42.82 & 0.0443 & 32.19 & 0.0749 & 18.24 \\
\hline $\ln \left(\sigma_{\text {revdate }} / \sigma_{\text {priordate }}\right)$ & 0.1969 & 6.75 & 0.1986 & 6.87 & 0.1895 & 6.51 \\
\hline signnews & & & $(0.0269)$ & (13.28) & $(0.0266)$ & (13.09) \\
\hline absnews & & & 11.5380 & 48.36 & 14.0031 & 52.32 \\
\hline log\#analysts & & & & & $(0.0122)$ & $(8.48)$ \\
\hline logISDindex & & & & & $(0.0172)$ & $(1.89)$ \\
\hline number observations & \multicolumn{2}{|c|}{156,539} & \multicolumn{2}{|c|}{156,539} & \multicolumn{2}{|c|}{152,908} \\
\hline adjusted $\mathrm{R}^{2}$ & \multicolumn{2}{|c|}{$0.03 \%$} & \multicolumn{2}{|c|}{$1.64 \%$} & \multicolumn{2}{|c|}{$2.07 \%$} \\
\hline
\end{tabular}

